TAO, Vol. 15, No. 5, 881-899, December 2004

\title{
Influence of Long-Range Transport Dust Particles on Local Air Quality: A Case Study on Asian Dust Episodes in Taipei during the Spring of 2002
}

\author{
Charles C.-K. Chou ${ }^{1, *}$, Chuan-Yao Lin ${ }^{1}$, Tze-Kuang Chen ${ }^{1}$, Shih-Chieh Hsu ${ }^{1}$, Shih-Chun Lung ${ }^{1}$, \\ Shaw Chen Liu ${ }^{1}$, and Chea-Yuan Young ${ }^{2}$
}

(Manuscript received 3 September 2003, in final form 23 April 2004)

\begin{abstract}
In the spring of 2002, an intensive field measurement campaign was conducted to investigate the impact of Asian dust transport on local air quality in Taipei, Taiwan. The mass concentration, size distribution and chemical composition of the atmospheric aerosols were measured. Air quality data collected by the Taiwan EPA during this period were also analyzed. It was found that the content of crustal elements in aerosols could drastically increase on the arrival of air masses transported from the desert areas in Northwestern China and Mongolia. Time series analysis of aerosol measurements, air quality data, and meteorological conditions identified six Asian dust transport episodes occurring in the spring of 2002. In order to apportion the ambient aerosol burden between local and long-range sources, nitrogen oxides $\left(\mathrm{NO}_{\mathrm{X}}\right)$ was chosen as a local pollution tracer and a simplified algorithm based on the $\mathrm{NO}_{\mathrm{X}}$ and $\mathrm{PM}_{10}$ correlation was proposed. It was estimated that long-range transported aerosols contributed as much as $87 \%$ to the $\mathrm{PM}_{10}$ in Taipei on Feb. 11, the most intense dust event in 2002. A weak event that occurred on Mar. 23 contributed $35 \%$ to the $\mathbf{P M}_{10}$. Our results indicate that the air quality impact due to Asian transport dust is still important even during weak dust events.
\end{abstract}

(Key words: Asian dust; Aerosol composition; Long-range transport; Air quality)

\footnotetext{
${ }^{1}$ Research Center for Environmental Changes, Academia Sinica, Taipei, Taiwan, ROC

2 Environmental Protection Administration, Taiwan, ROC

* Corresponding author address. Dr. Charles C. K. Chou, Research Center for Environmental Changes, Academia Sinica, Taipei, Taiwan, ROC;E-mail: ckchou@rcec.sinica.edu.tw
} 


\section{INTRODUCTION}

In the springtime, extreme weather conditions such as intense fronts and strong surface winds are induced frequently over Northwestern China and Mongolia. Mineral particles can be lifted up by the surface winds over the desert and loess areas in this region and injected into the troposphere following intense convection. The mineral particles are then transported to Northeastern Asia and usually result in serious deterioration in local air quality (e.g., Iwasaka et al. 1983; Hursar et al. 2001; Murayama et al. 2001; Kim et al. 2003). Sometimes, Asian dust transport can even be observed in the North Pacific Ocean and North America (e.g., Duce et al. 1980; Shaw 1980; Uematsu et al. 1983; Jaffe et al. 1999; Mckendry et al. 2001; Tratt et al. 2001; VanCuren and Cahill 2002). Although the Asian dust particles are carried mostly by westerly winds and spread over the mid-latitudes, a portion of the dust particles can also be transported to Taiwan under the prevailing northeasters of the winter monsoon.

Public concern regarding the long-range transport of Asian dust has arisen in Taiwan due to its impact on the local air quality and, consequentially, public health. It was recorded that the $\mathrm{PM}_{10}$ concentration (particulate matter with aerodynamic diameter less than $10 \mu \mathrm{m}$ ) increased to a level higher than $400 \mu \mathrm{g} \mathrm{m}^{-3}$ in an intense dust event that occurred in April 2000 (Lin 2001). Recently, this concern has increased due to the co-transport of anthropogenic pollutants and dust in the Asian outflows. To evaluate this health hazard, it is critical to determine the amount of particulate pollutants transported from the Asian continent during these dust events. This is not an easy task, because there are substantial local sources of air pollutants, particularly in urban areas.

To assess the impact of Asian dust on local air quality, an intensive aerosol experiment was implemented in Taipei during the spring of 2002. In this paper, we use the aerosol measurements made during the campaign and the gaseous pollutant mixing ratios measured concurrently at the Taiwan-EPA's air-quality monitoring stations to estimate the contribution from long-range transport to the atmospheric aerosol burden for each dust episode. We used mineral elements as tracers for the Asian dust, while $\mathrm{NO}_{\mathrm{X}}$ was selected as the tracer for local pollution. The latter was selected because, in an analysis of temporal variations in air pollutants during Asian dust events, Lin et al. (2004) noticed that $\mathrm{NO}_{\mathrm{X}}$ tended to represent local pollution the best as relatively little $\mathrm{NO}_{\mathrm{X}}$ came from long-range transport.

\section{FIELD CAMPAIGN AND DATASET}

The campaign period of this study was from February to May in 2002. The Taiwan Air Quality Model (TAQM) was used to simulate Asian dust transport and forecast the occurrence of a dust episode in Taiwan (Liu et al. 2004). Aerosol sampling for $\mathrm{PM}_{10}$ and $\mathrm{PM}_{2.5}$ started one day before the forecast "dust day" and lasted one week for each dust event. In addition, for comparison purposes, a non-dust experiment was arranged from May 27 to 31 to collect aerosol samples for "normal" days. The sampling equipment was located on the main building of the Central Weather Bureau (CWB) in Taipei, Taiwan. Figure 1 shows the geographical location of the sampling site. The sampling period for each sample set was 12 hours. Daytime 
samples were collected from 0800LST to 2000LST and nighttime sampling was from 2000LST to 0800LST the next day. Aerosol mass concentrations were determined by gravimetric measurement of the PTFE membrane filters before and after the sampling activities. The PTFE filter samples were also used for ionic species and crustal element analyses. The details of the chemical analyses are presented in separate papers in this special issue (Hsu et al. 2004; Lung et al. 2004). Besides, a redundant sample set was collected on pre-fired quartz filters for analyzing carbonaceous species (i.e., organic carbon and elemental carbon) in aerosols. The analysis method for the carbonaceous species was following the thermal/optical reflectance (TOR) protocol (Chow et al. 1993).

In addition to the measurements described above, data from the Taiwan Air Quality Monitoring Network (TAQMN), which belongs to the official air quality monitoring system of the Taiwan EPA, were analyzed to examine potential Asian dust episodes. The TAQMN consists of 72 air-quality monitoring stations and provides highly time-resolved air quality data from all over the island. All instruments in these stations are maintained and periodically calibrated according to the TAQMN Quality Management Plan. In this work, data sets from the Wan-Li and $\mathrm{Ku}$-Tin stations were analyzed: Wan-Li is a remote station located near the northern tip of Taiwan and is upwind from Taipei under the northeastern monsoons. Ku-Tin is a representative downtown station in Taipei. The geographical locations of the two TAQMN stations are also shown in Fig. 1.

\section{RESULTS AND DISCUSSION}

\subsection{Identification of Asian Dust Episodes}

The daily average $\mathrm{PM}_{10}$ concentrations over downtown Taipei are generally around $40-60 \mu \mathrm{g} \mathrm{m}^{-3}$ in the spring. Figure 2 shows the time series of hourly $\mathrm{PM}_{10}$ levels at the Wan$\mathrm{Li}$ and $\mathrm{Ku}$-Tin stations between Feb. 1 and Apr. 30, 2002. One can see that several "peaks" over $100 \mu \mathrm{g} \mathrm{m}^{-3}$ occurred concurrently at Wan-Li and Ku-Tin. These high $\mathrm{PM}_{10}$ episodes are usually attributed to Asian dust transport. However, the increase in aerosol concentration is not necessarily related to dust storms. Either long-range transport of particulate pollutant or pollution from local sources can also result in a high $\mathrm{PM}_{10}$ event.

Lin et al. (2004) developed an objective method to distinguish long-range transport air masses from local pollution. They reported that the diurnal cycle of local pollutants would disappear when a long-range transported air parcel arrived and dominated the local air quality. Accordingly, a high $\mathrm{PM}_{10}$ episode will be identified as a "suspected Asian dust transport case", if

- a drastic increase in the $\mathrm{PM}_{10}$ concentration occurs within a few hours after the arrival of a cold front that originated in the Asian continent, and

- local pollutant (like $\mathrm{NO}_{\mathrm{X}}$ and $\mathrm{CO}$ ) concentrations decrease to a low and steady level at the same time.

Following these rules, eight of the $\mathrm{PM}_{10}$ peaks in Fig. 2 (which occurred on Feb. 9 - 11, Mar. 6, Mar. 18, Mar. 23, Apr. 9 - 10, and Apr. 18) were suggested as results of Asian dust 


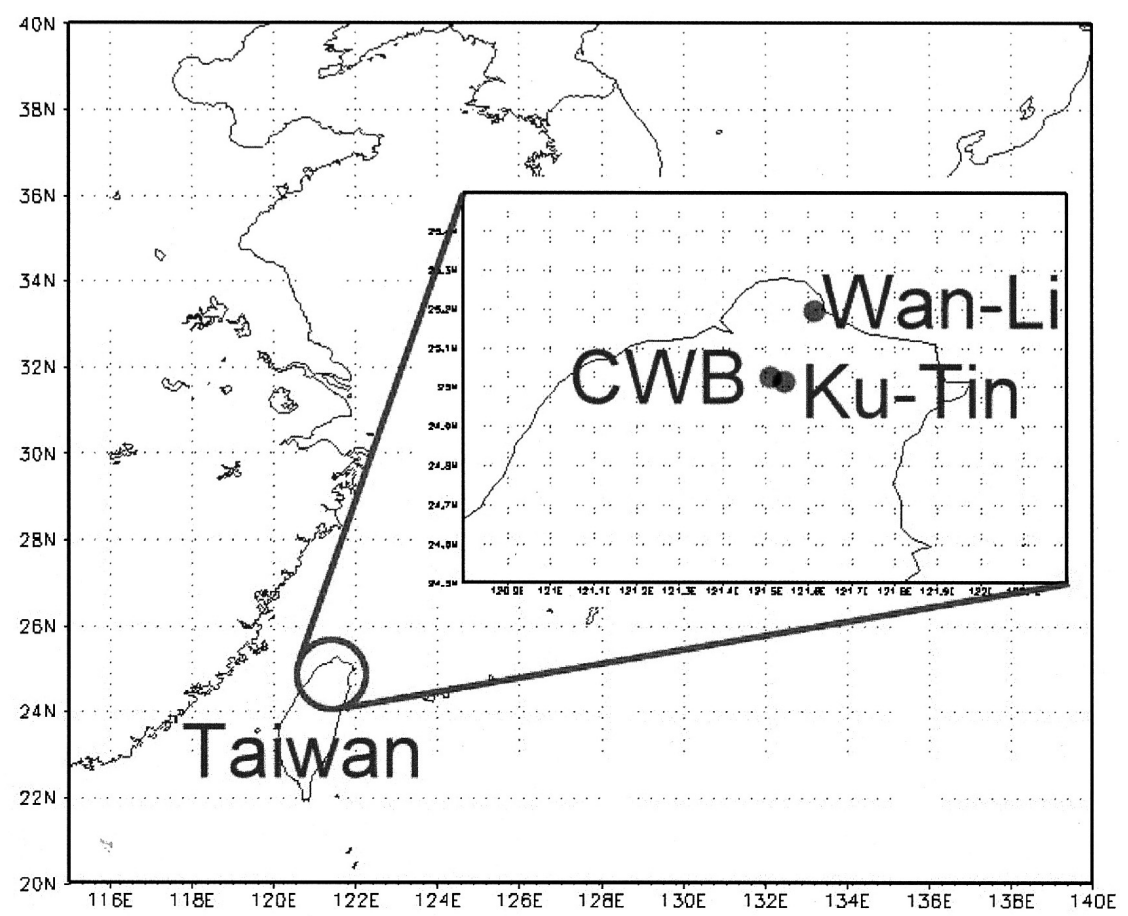

Fig. 1. Geographic locations of the sampling site (CWB) and the air-quality monitoring stations (Ku-Tin and Wan-Li) of Taiwan EPA.

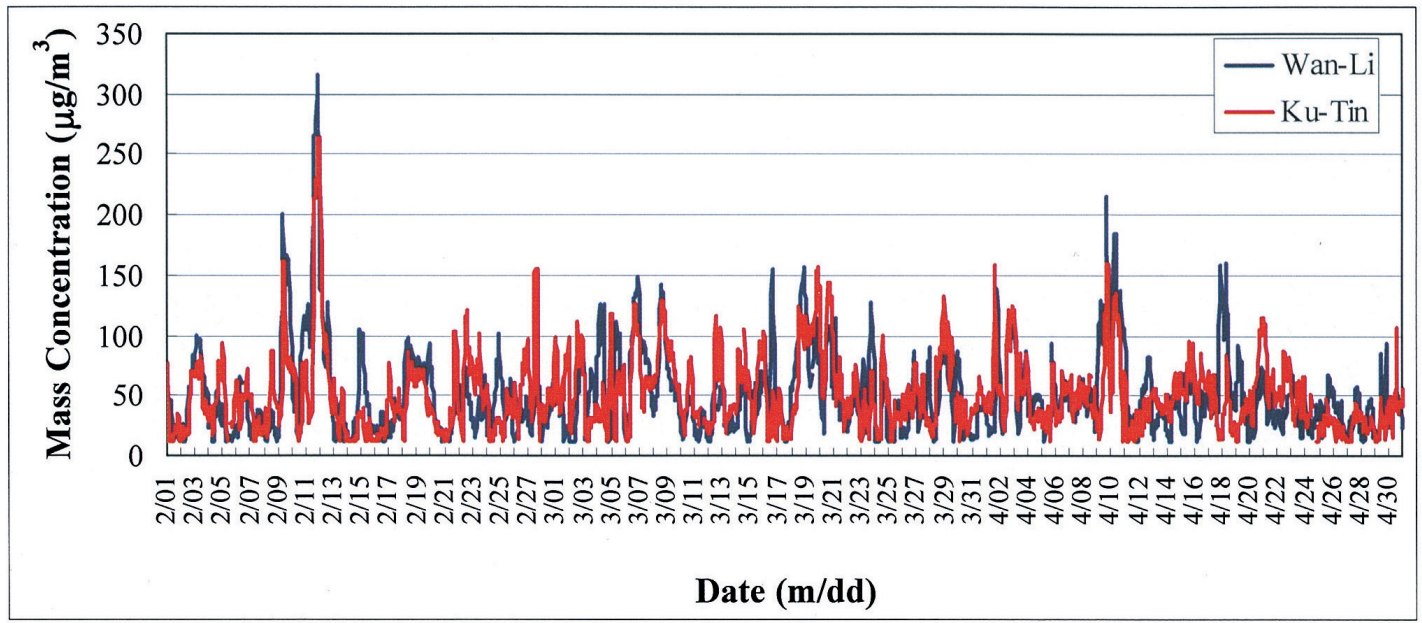

Fig. 2. Variations in $\mathrm{PM}_{10}$ concentrations at the EPA's Ku-Tin and Wan-Li stations during spring 2002. 
transport. Figures 3 and 4 show the temporal variations in air pollutants during those periods at Wan-Li and Ku-Tin, respectively. The pattern of the time series plots for the Wan-Li's air quality data agrees well with the results from Lin et al. (2004). However, that for the Ku-Tin's data shows some inconsistent points. First, when air parcels with dust arrived and increased the $\mathrm{PM}_{10}$ level at Wan-Li, air pollution from local sources in Taipei was still obvious, as indicated by the high levels of $\mathrm{NO}_{\mathrm{X}}$ at Ku-Tin. Given that the Wan-Li station is located near the northern tip of Taiwan, the strong and prevailing northeaster associated with frontal passage can sweep the local pollutants away with the arrival of a cold front. However, due to the geographical features of Taipei, the surface wind in the Taipei basin is significantly weaker and can only blow a portion of the local pollutants out. Thus, it is rather difficult to identify a dust episode using the time series pattern of air pollutant concentrations in the Taipei downtown area if the dust event is not strong enough to dominate the air quality. Second, changes in air quality patterns at Ku-Tin on Mar. 23 and Apr. 18 were likely due to local pollution, whereas the air quality patterns at Wan-Li clearly show dust transport characteristics. The differences show that the dust signals can be masked by heavy pollution in the downtown area in a weak dust event. A particular case occurred on Mar. 8. A "dust parcel" came with a cold front on Mar. 6 and resulted in a typical dust event. The $\mathrm{PM}_{10}$ levels declined at both Wan-Li and KuTin on Mar. 7 and then concurrently increased on Mar. 8. The air quality data from the WanLi station on Mar. 8 showed signs of local pollution; however, relatively low $\mathrm{CO}$ and $\mathrm{NO}_{\mathrm{X}}$ mixing ratios occurred at $\mathrm{Ku}$-Tin, suggesting the high $\mathrm{PM}_{10}$ episode was an Asian dust transport case. Figures $3 \mathrm{~b}$ and $4 \mathrm{~b}$ show that the increase in $\mathrm{PM}_{10}$ on Mar. 8 followed a change in wind direction from a southwesterly to an easterly. Thus, a possible explanation for this case is that, as the center of the high-pressure system moved to the east of Taiwan, its circumfluence brought some dust back and generated a mixture of dust and local pollutants.

Information concerning the aerosol chemical compositions is essentially the best evidence of a dust event. In general, the Taipei aerosols are composed mostly of ionic and carbonaceous species. Figure 5 illustrates the chemical compositions of aerosol samples collected during the Asian dust episodes and the non-dust period in this work. The ionic species $\left(\mathrm{NH}_{4}{ }^{+}, \mathrm{SO}_{4}{ }^{2-}\right.$, and $\mathrm{NO}_{3}{ }^{-}$) and total carbon (TC) accounted for 24 and $22 \%$ of the average $\mathrm{PM}_{10}$ concentration during the dust episodes. Both were significantly lower than their non-dust counterpart (36 and 29\%). The change in the abundance of crustal elements (e.g., $\mathrm{Al}, \mathrm{Ca}, \mathrm{Fe}, \mathrm{Mn}$, etc.) in the ambient aerosols was quite obvious. It increased from about $5 \%$ on the normal days to $22 \%$ for dust episodes.

Figure 6 shows the time series for the $\mathrm{PM}_{10}$ and aluminum concentrations (in $\mathrm{PM}_{10}$ ) measured during our field campaign. A detailed discussion on all the crustal elements is presented in a separate paper in this issue (Hsu et al. 2004). Comparing our elemental measurement with the $\mathrm{PM}_{10}$ concentrations, six of the $\mathrm{PM}_{10}$ peaks in Fig. 2 (occurring on Feb. 11, Mar. 6, Mar. 8, Mar. 18, Mar.23 and Apr. 9) were identified as dust events, because the $\mathrm{PM}_{10}$ concentration increased coincidentally with the increase in the aluminum level. We validated this rule by applying it to the data for the non-dust experiment: $\mathrm{PM}_{10}$ showed a typical diurnal variation between May 27 and 31, whereas aluminum stayed at a low and steady level in the same period. Dust transport episode identification using aluminium abundance was used to check the suspected episodes suggested by the air quality method. The high level of crustal 
(a)

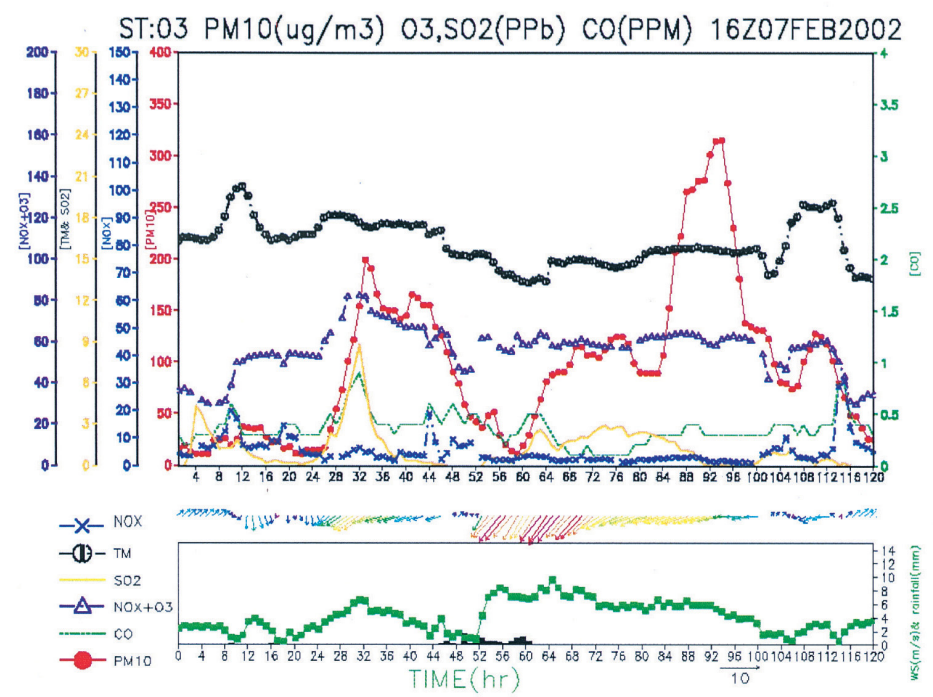

(b)

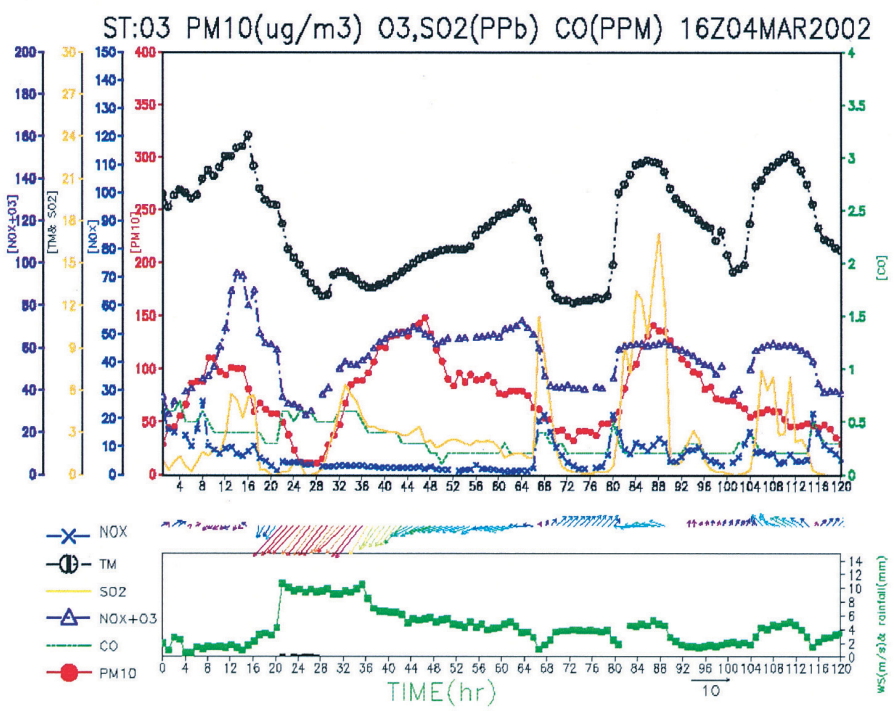

Fig. 3. The time series of hourly $\mathrm{PM}_{10}$ (red closed circles), $\mathrm{CO}$ (dashed line), $\mathrm{SO}_{2}$ (solid line), $\mathrm{NO}_{\mathrm{X}}+\mathrm{O}_{3}$ (triangle), $\mathrm{NO}_{\mathrm{X}}$ (cross), surface temperature (open circle with vertical line), wind speed (closed squares, bottom panel), and rainfall (black bar, bottom panel) measured at EPA's Wan-Li station during six high $\mathrm{PM}_{10}$ periods. The surface wind is presented using wind vector: (a) 0100LST Feb. 8 to 2400LST Feb. 12; (b) 0100LST Mar. 5 to 2400LST Mar. 9; (c) 0100LST Mar. 16 to 2400LST Mar. 20; (d) 0100LST Mar. 21 to 2400LST Mar. 24; (e) 0100LST Apr. 8 to 2400LST Apr. 12; (f) 0100LST Apr. 17 to 2400LST Apr. 20. 
(c)
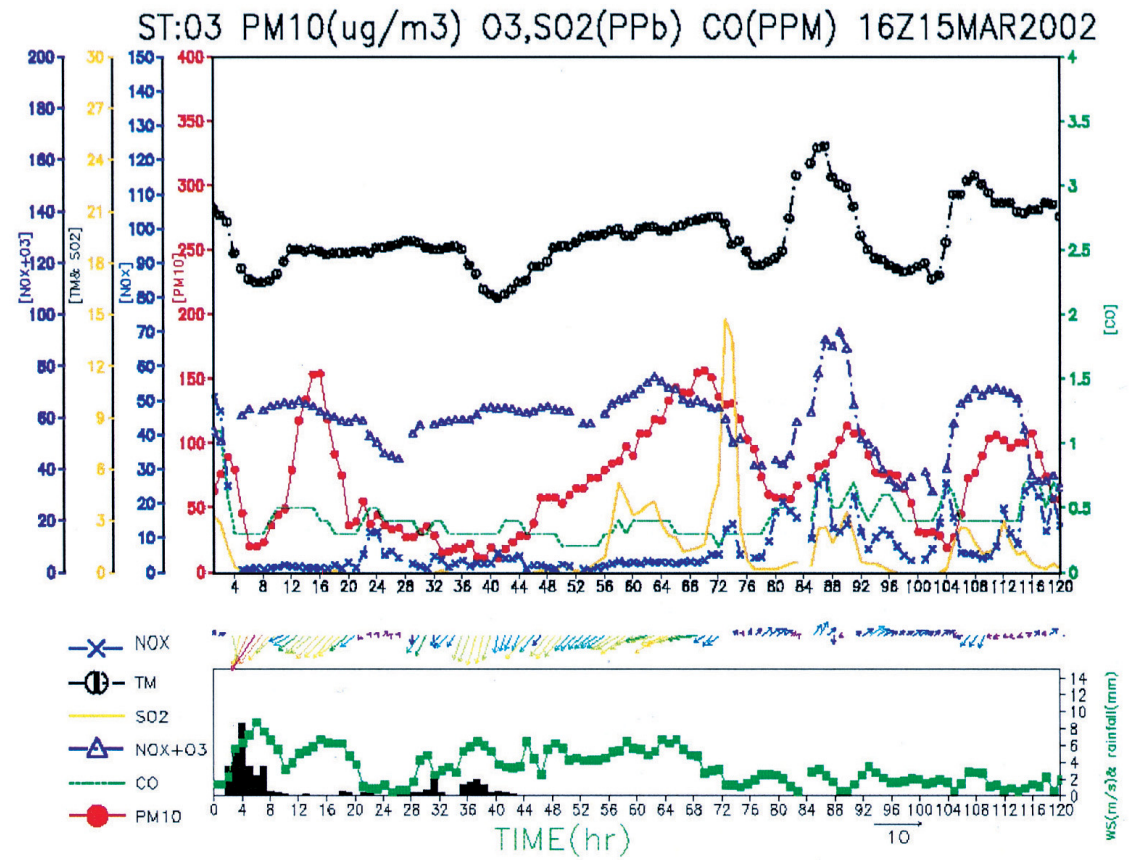

(d)
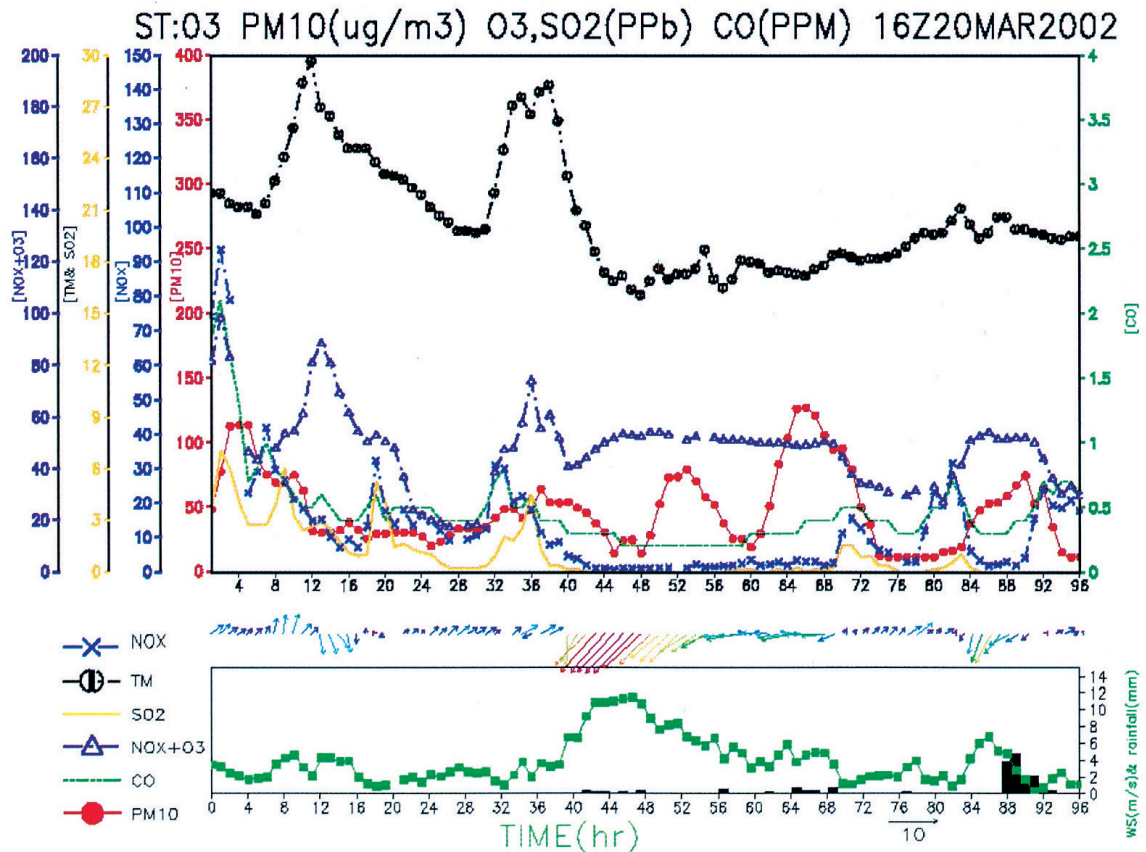

Fig. 3. Continued. 
(e)

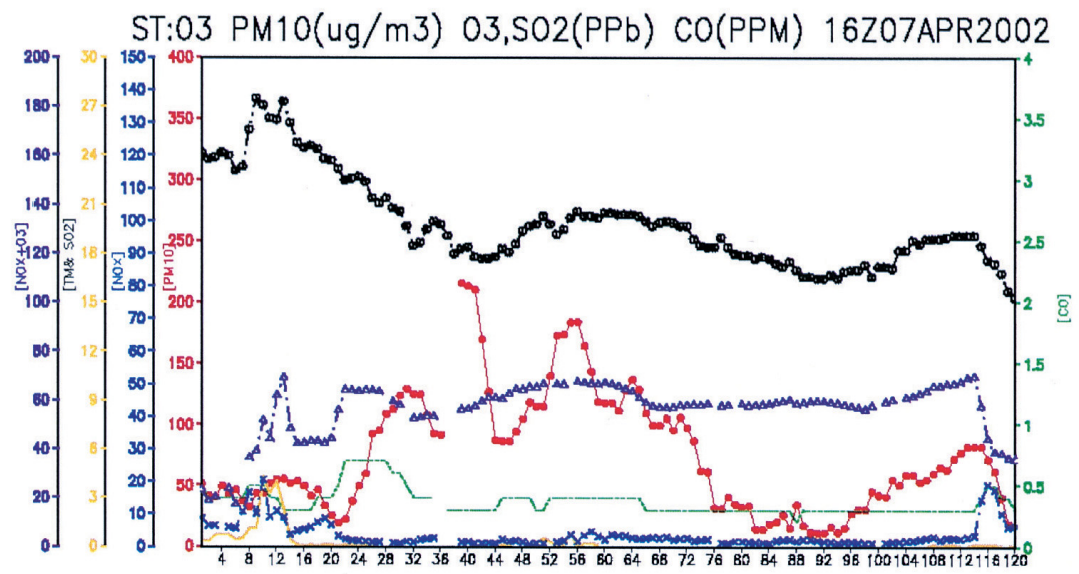

(f)

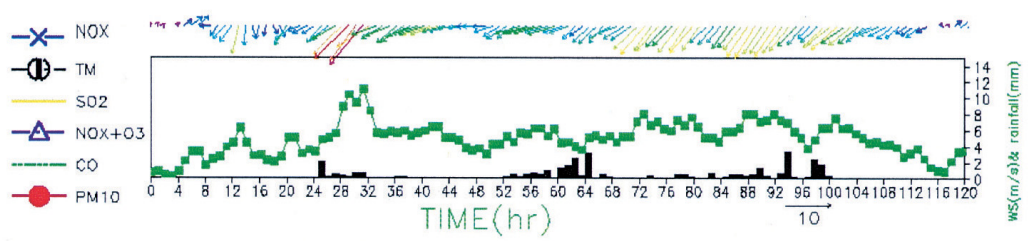

ST:03 PM10(ug/m3) 03,S02(PPb) CO(PPM) 16Z16APR2002
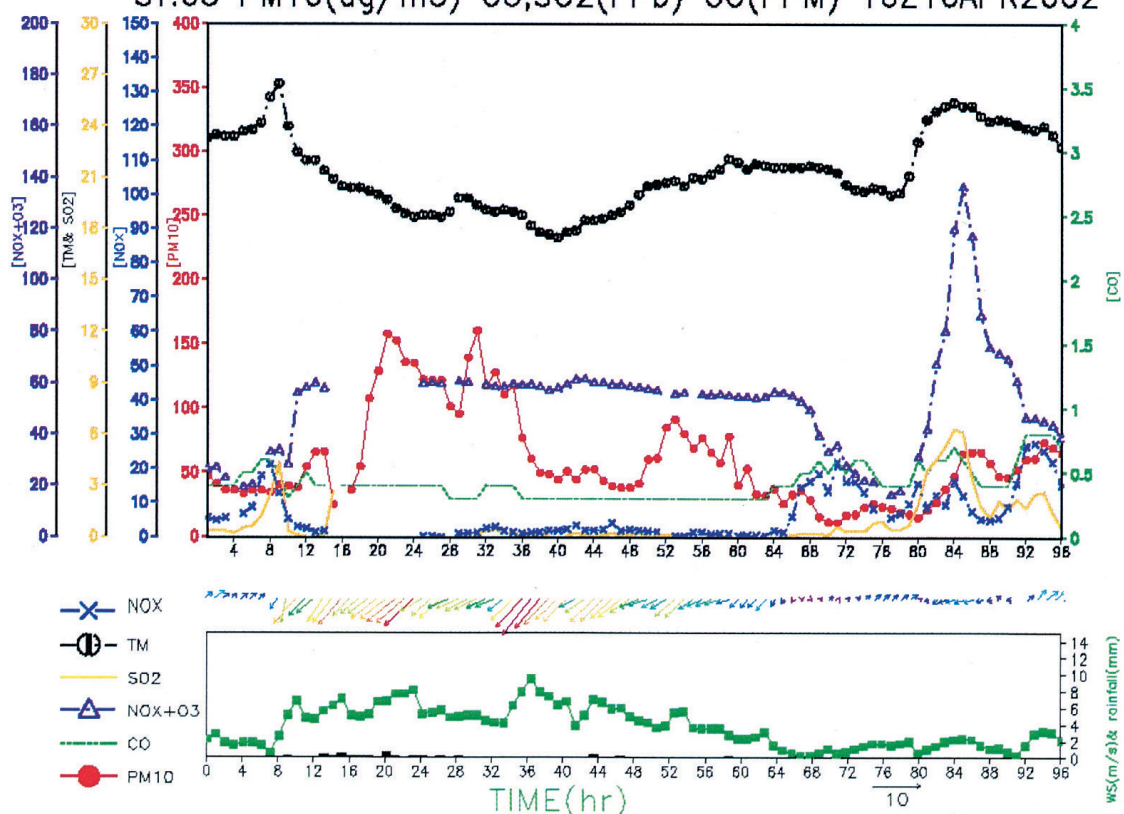

Fig. 3. Continued. 
(a)

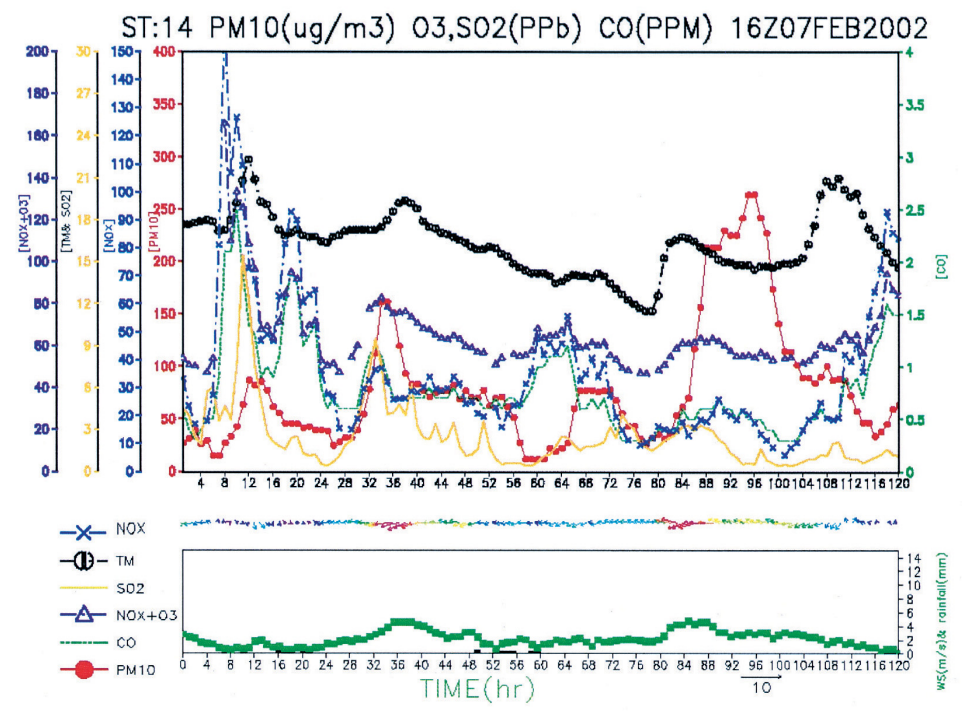

(b)

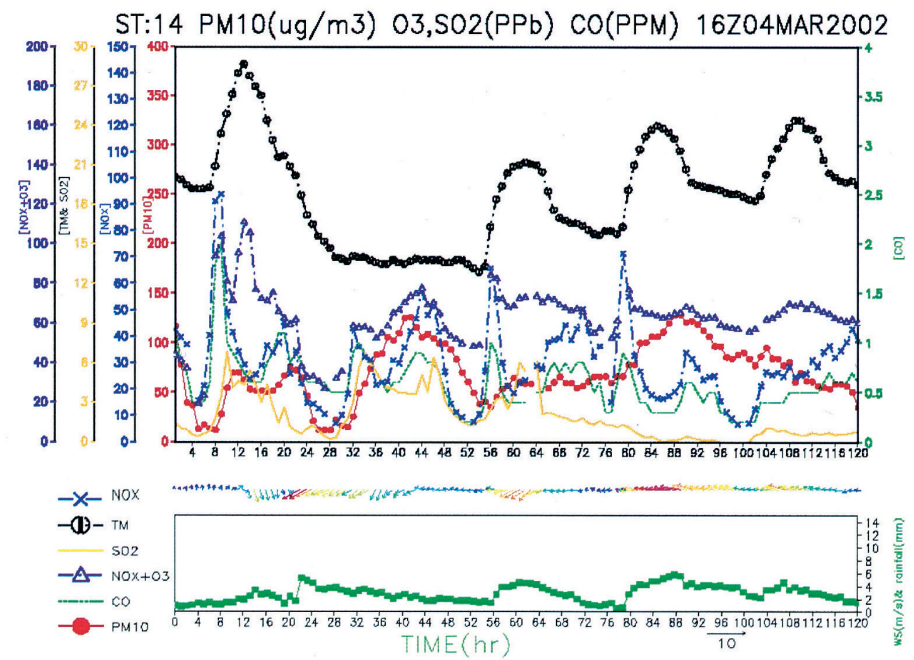

Fig. 4. The time series of hourly $\mathrm{PM}_{10}$ (red closed circles), $\mathrm{CO}$ (dashed line), $\mathrm{SO}_{2}$ (solid line), $\mathrm{NO}_{\mathrm{X}}+\mathrm{O}_{3}$ (triangle), $\mathrm{NO}_{\mathrm{X}}$ (cross), surface temperature (open circle with vertical line), wind speed (closed squares, bottom panel), and rainfall (black bar, bottom panel) measured at EPA's Ku-Tin station during six high $\mathrm{PM}_{10}$ periods. The surface wind is presented using wind vector: (a) 0100LST Feb. 8 to 2400LST Feb. 12; (b) 0100LST Mar. 5 to 2400LST Mar. 9; (c) 0100LST Mar. 16 to 2400LST Mar. 20; (d) 0100LST Mar. 21 to 2400LST Mar. 24; (e) 0100LST Apr. 8 to 2400LST Apr. 12; (f) 0100LST Apr. 17 to 2400LST Apr. 20. 
(c)

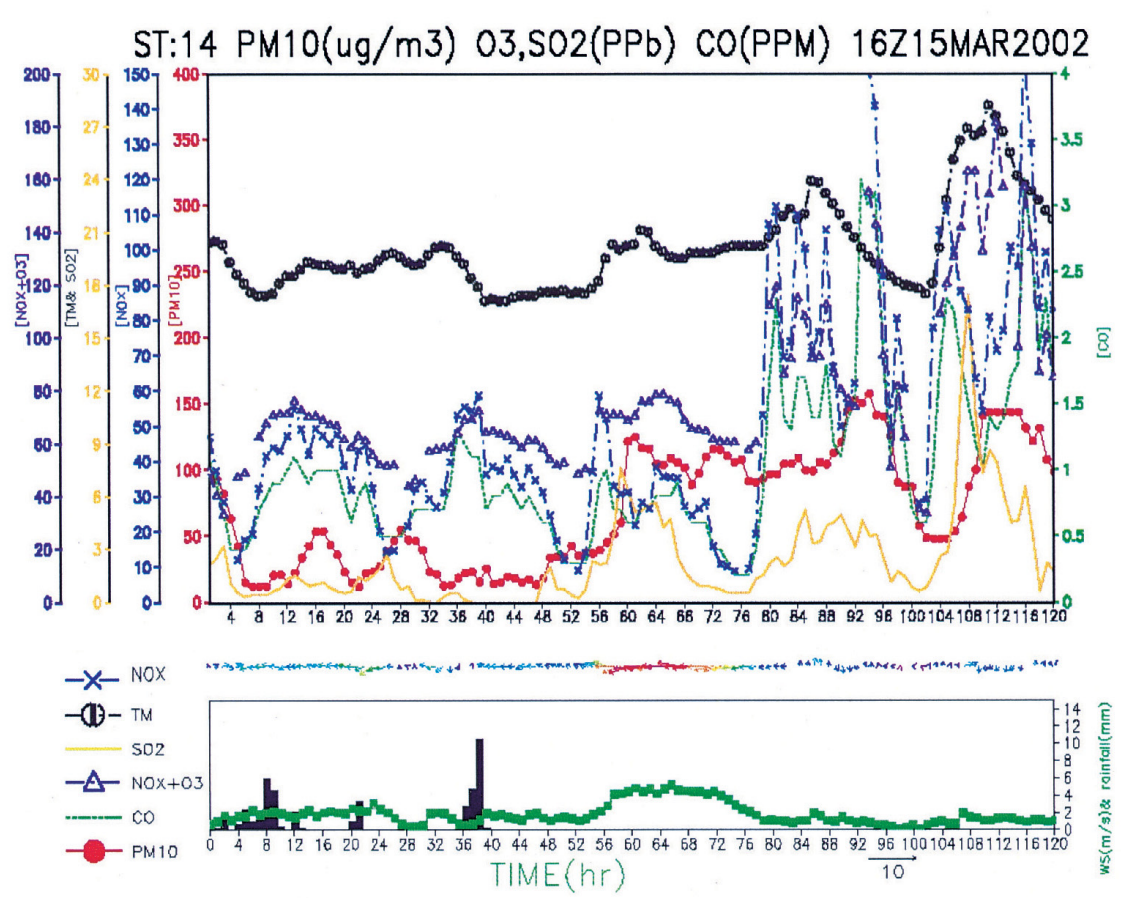

(d)
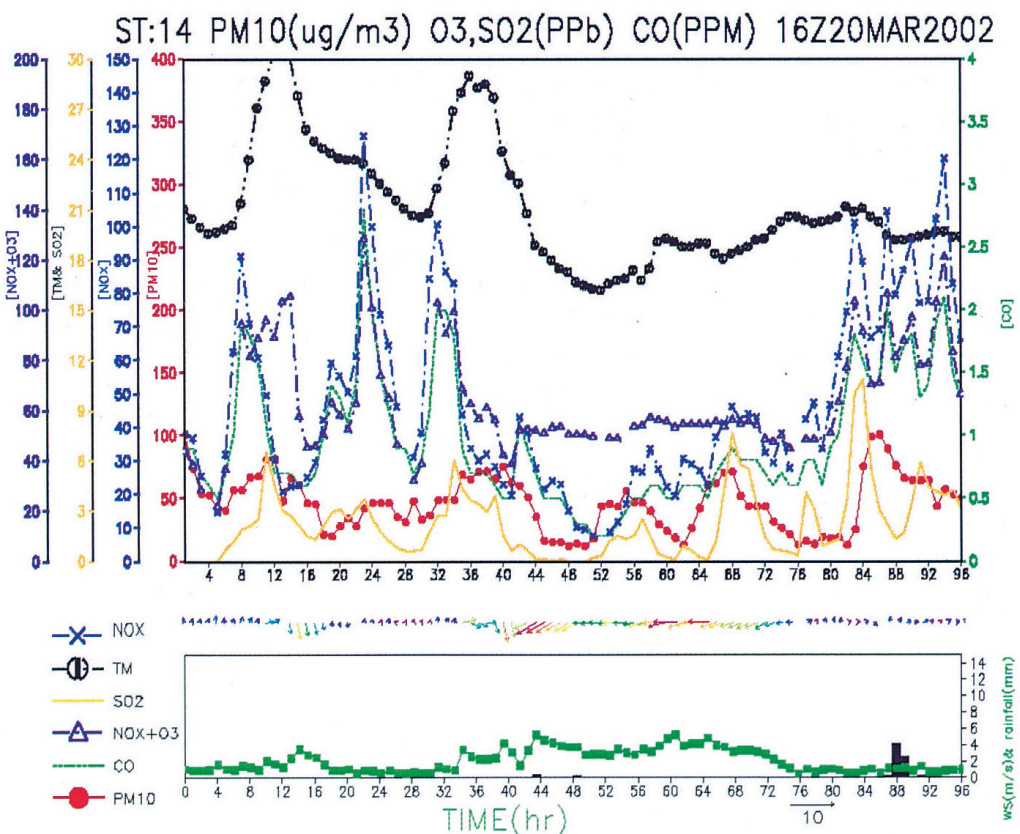

Fig. 4. Continued. 
(e)

ST:14 PM10(ug/m3) 03,S02(PPb) CO(PPM) 16Z07APR2002
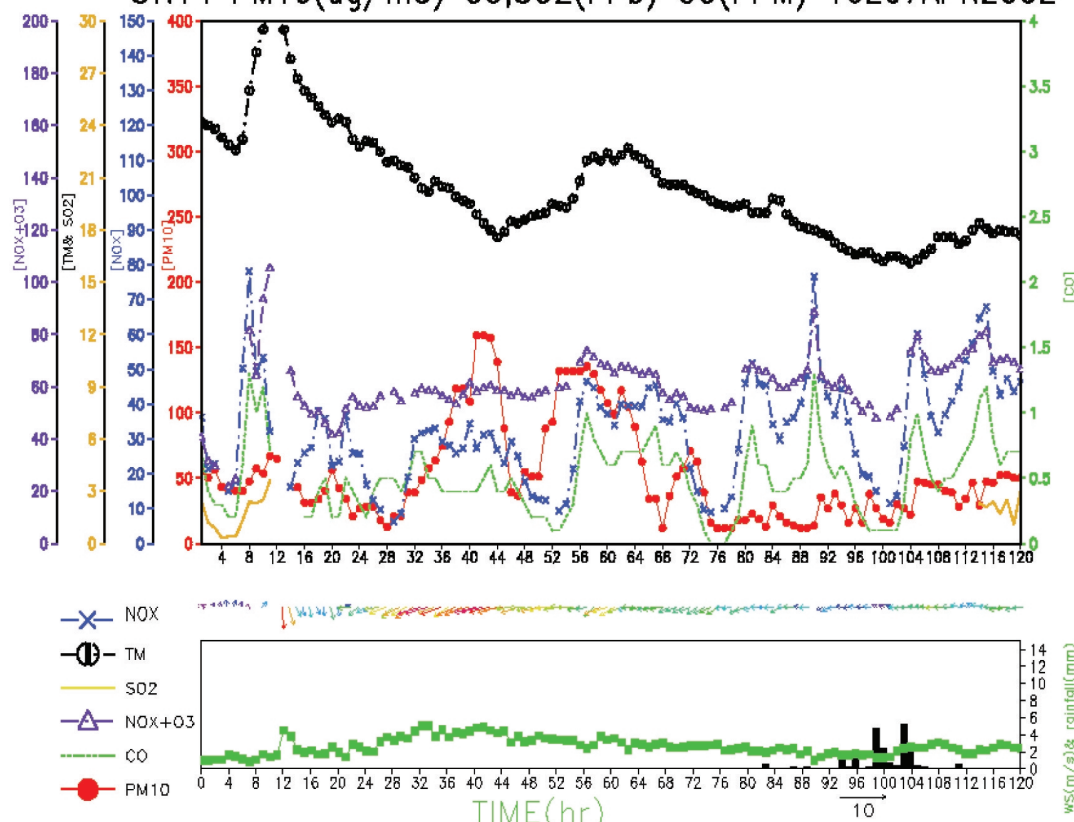

(f)

ST:14 PM10(ug/m3) 03,S02(PPb) CO(PPM) 16Z16APR2002
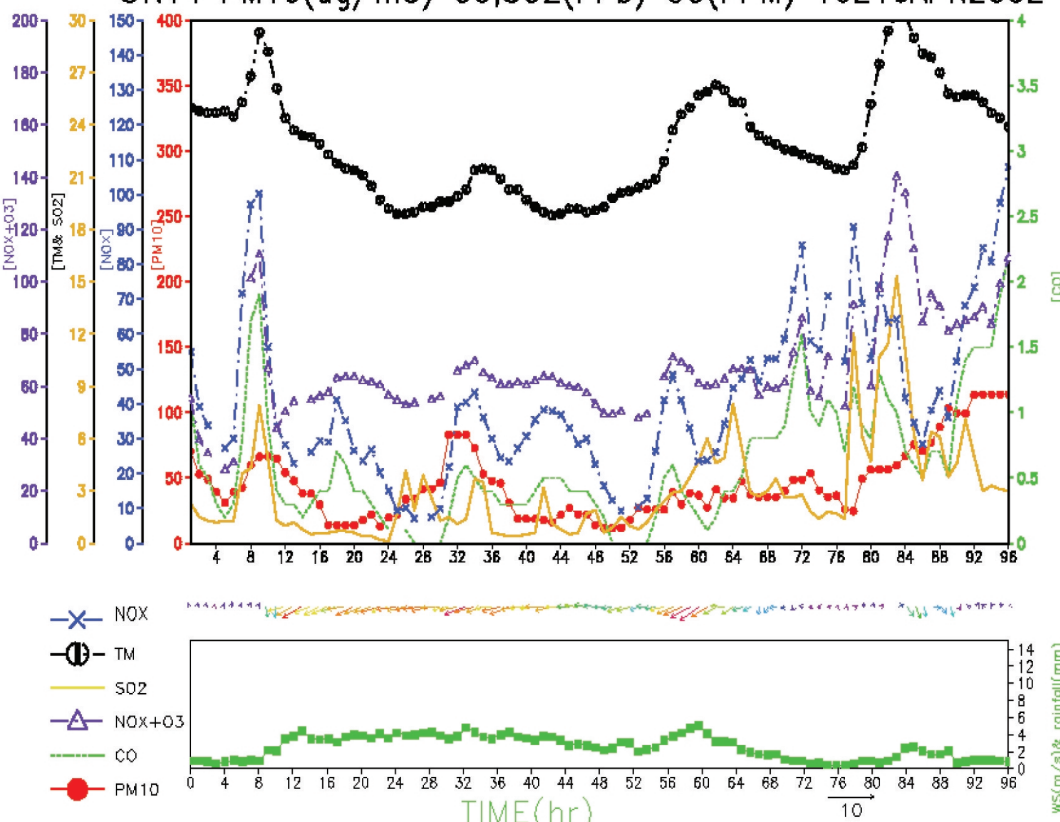

Fig. 4. Continued. 
(a) Dust Campaign

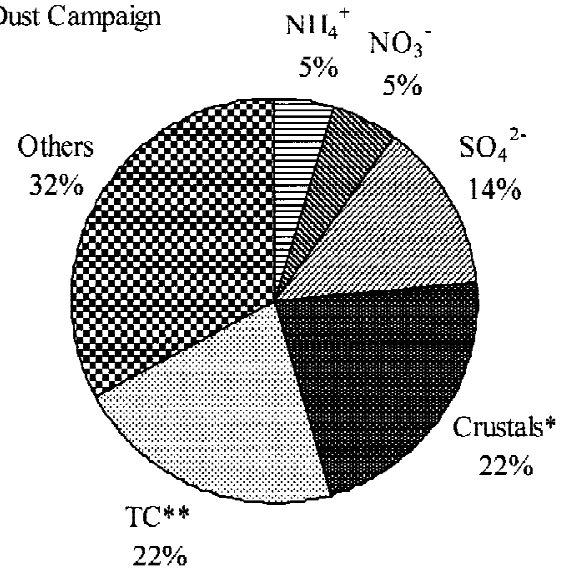

(b) Non-Dust Campaign

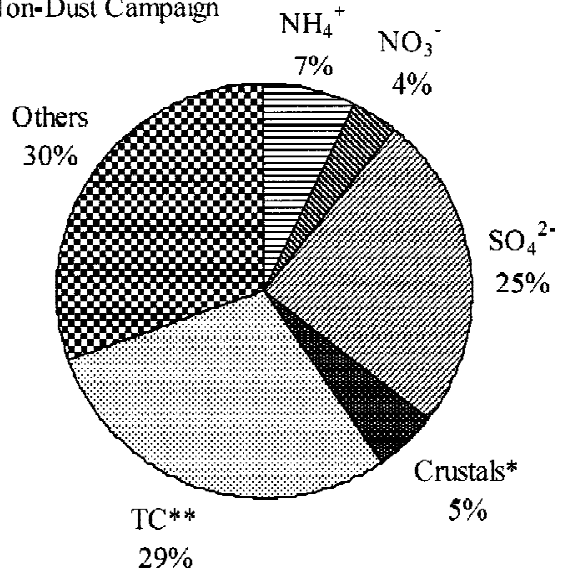

* Sum of all the crustal elements analyzed in this work

** Sum of organic carbon and element carbon

Fig. 5. Average chemical compositions of aerosol samples collected during (a) the dust episodes and (b) the non-dust experiment period.

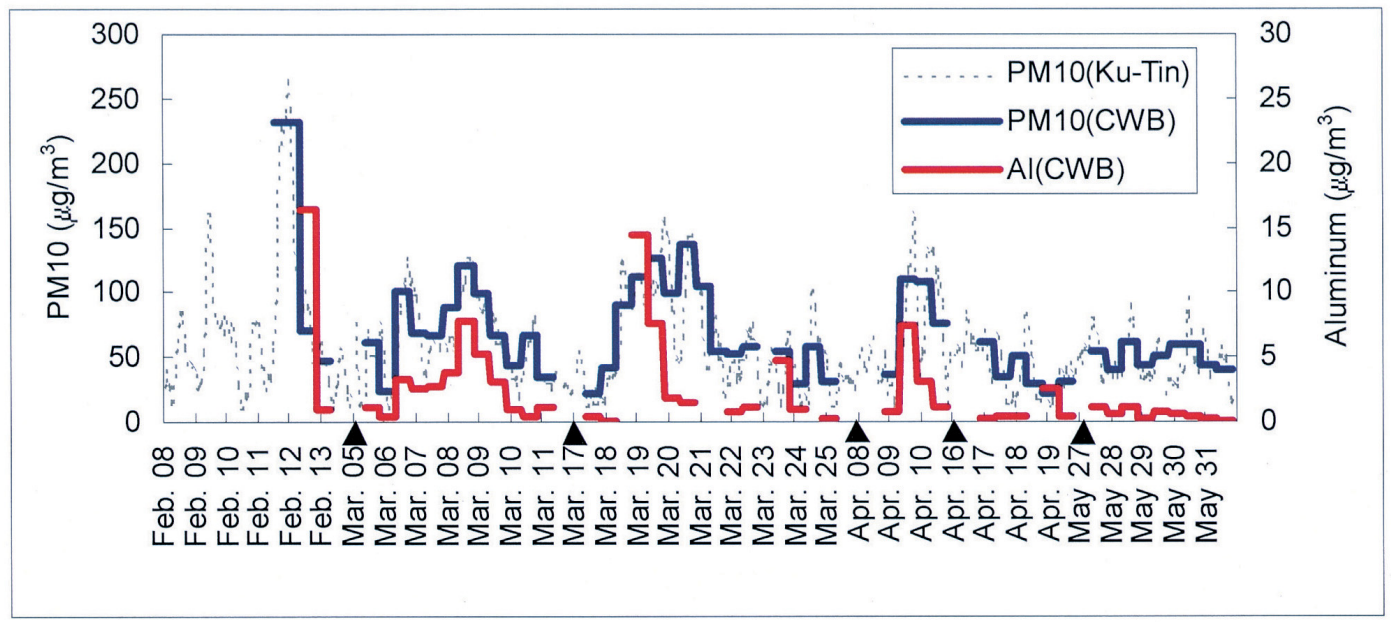

Fig. 6. Time series for the $\mathrm{PM}_{10}$ and aluminum concentrations at CWB, Taipei over the field campaign. The hourly $\mathrm{PM}_{10}$ concentration measured at EPA's Ku-Tin station is also plotted for comparison. The black triangles indicate the break points on the time axis. 
elements in the aerosols confirmed the suspected cases on Mar. 8 and Mar. 23, whereas the low aluminum content showed that the Asian dust contribution to Taipei's aerosols was low on Apr. 10 and Apr. 18. However, the high $\mathrm{PM}_{10}$ episode on Feb. 9 remained a suspected case, because we do not have aerosol composition measurements to confirm it as a dust event.

In summary, five Asian dust episodes and one suspected case were identified according to the general meteorological conditions, time series pattern of air pollutant concentrations, and the abundance of aluminum in the aerosols. Unfortunately, our intermittent aerosol composition measurements left the origins of some high $\mathrm{PM}_{10}$ episodes uncertain. Table 1 lists the periods of respective identified dust episodes in Taipei in the spring of 2002. The maximum hourly $\mathrm{PM}_{10}$ concentrations at the Wan-Li and $\mathrm{Ku}$-Tin stations are also listed. Note that the features of weak dust events could be masked by local pollution in the downtown area, and therefore, we cannot rule out the possibility that some weak cases occurred beyond the periods listed here.

\subsection{Asian Dust Contributions to the Local Aerosol Concentrations}

After establishing the dust event periods, we tried to estimate the contribution of Asian dust to the aerosol burden, which is important for a quantitative assessment of the environmental impact. To address this issue, a local pollution tracer was needed. The first characteristic of a good tracer is a robust correlation with $\mathrm{PM}_{10}$ in the local pollution air mass. With this feature, the tracer can be used to estimate local contribution to the ambient aerosols during a dust event. Figures $7 \mathrm{a}, \mathrm{b}$ and $\mathrm{c}$ show the correlations between $\mathrm{PM}_{10}$ and the gaseous pollutants (NOx, $\mathrm{CO}$, and $\mathrm{SO}_{2}$ ) in their monthly average concentrations at Ku-Tin in 2002. $\mathrm{PM}_{10}$ correlates strongly with $\mathrm{NO}_{\mathrm{X}}$, moderately with $\mathrm{CO}$, and weakly with $\mathrm{SO}_{2}$. Good correlations suggest the similar source processes between the pollutants: $\mathrm{PM}_{10}, \mathrm{NO}_{\mathrm{X}}$, and $\mathrm{CO}$ come mainly from vehicular exhaust emissions in Taipei, whereas $\mathrm{SO}_{2}$ comes mostly from industrial sources (e.g., power plants). Despite the emission sources, the atmospheric lifetime of a pollutant can affect its temporal variation pattern and, consequently, its correlation with other species. The lifetime of $\mathrm{NO}_{\mathrm{X}}$ is comparable to that of $\mathrm{PM}_{10}$, while $\mathrm{CO}$ can survive longer in the troposphere. Hence, $\mathrm{NO}_{\mathrm{X}}$ is expected to track the variation in $\mathrm{PM}_{10}$ more closely and with a better correlation than $\mathrm{CO}$. The second characteristic that a good tracer for local pollution must have is a relatively low mixing ratio in long-range transported air masses. If the dust storm air masses originate in remote clean regions, they should not contain high levels of urban pollutants. When the air parcels pass through Northern and Eastern China, they may pick up some air pollutants via vertical mixing in the boundary layer and then carry the pollutants together with the dust. Among the air pollutants regularly monitored at the TAQMN stations, $\mathrm{NO}_{\mathrm{X}}$ is the most reactive species with a lifetime of only around 1 day in urban areas (Seinfeld and Pandis 1998). Thus, the mixing ratio of $\mathrm{NO}_{\mathrm{X}}$ in aged air masses should be significantly lower than that in urban areas. This expectation is consistent with the observations shown in Fig. 3: The mixing ratio of $\mathrm{NO}_{\mathrm{X}}$ remained at a level of only a few ppb during the periods with strong and prevailing northeasters at Wan-Li. In addition to coming from a clean area, heterogeneous reactions between the $\mathrm{NO}_{\mathrm{X}}$ and the alkali dust particles can further reduce the mixing ratios of $\mathrm{NO}_{\mathrm{X}}$ in the air parcels. It has been proven that nitrate can be formed via heterogeneous reac- 
Table 1. Periods and particulate measures for identified Asian dust episodes in Taipei.

\begin{tabular}{|c|c|c|c|c|}
\hline \multirow[t]{2}{*}{ Episode } & \multirow{2}{*}{$\begin{array}{c}\text { Event Period }{ }^{(a),(b)} \\
\text { (Starting Time/Date } \sim \text { Ending Time/Date) }\end{array}$} & \multirow{2}{*}{$\begin{array}{l}\text { Peak }^{(\mathrm{c})} \\
\text { (Time/Date) }\end{array}$} & \multicolumn{2}{|c|}{ Max. Hourly $\mathrm{PM}_{10}\left(\mu \mathrm{g} / \mathrm{m}^{3}\right)$} \\
\hline & & & Wan-Li & Ku-Tin \\
\hline \multicolumn{5}{|c|}{ Confirmed episode } \\
\hline $\mathrm{C} 1$ & $9: 00 /$ Feb. $11^{(\mathrm{d})} \sim 19: 00 /$ Feb. 12 & 23:00/Feb. 11 & 315 & 264 \\
\hline $\mathrm{C} 2$ & 6:00/Mar.6 5:00/Mar. 10 & 16:00/Mar. 8 & 136 & 128 \\
\hline $\mathrm{C} 3$ & 4:00/Mar. $18 \sim 6: 00 /$ Mar. 20 & 12:00/Mar. 18 & 156 & 125 \\
\hline $\mathrm{C} 4$ & 1:00/Mar. $23 \sim 3: 00 /$ Mar. 24 & 19:00/Mar. 23 & 127 & 71 \\
\hline $\mathrm{C} 5$ & 3:00/Apr. $9 \sim 22: 00 /$ Apr. 9 & 17:00/Apr. 9 & 216 & 159 \\
\hline \multicolumn{5}{|c|}{ Suspected episode } \\
\hline S1 & 1:00/Feb. $9 \sim 10: 00 /$ Feb. 10 & 10:00/Feb. 9 & 200 & 161 \\
\hline
\end{tabular}

(a) The starting point is defined by the time $\mathrm{PM}_{10}$ begins to continuously increase to the $\mathrm{PM}_{10}$ peak during a dust episode, confirmed by the abundance of aluminum in the aerosols and from the air quality inspection.

(b) The ending point is defined using the time $\mathrm{PM}_{10}$ stops decreasing from the peak and both the air quality inspection and aluminum abundance show that the episode has passed.

(c) The peak point is defined at the time both $\mathrm{PM}_{10}$ and the aluminum concentrations reach their maximum.

(d) Because the aerosol sampling was started at 1200LST, Feb. 11, the starting time for this episode was determined solely using the results of time series analysis of air quality data.

tions between $\mathrm{NO}_{\mathrm{X}}$ and mineral particles (Mamane and Gottlieb 1989; Zhang et al. 2003). Consequently, using $\mathrm{NO}_{\mathrm{X}}$ as the local pollution tracer during Asian dust episodes was justified.

Figure 8 shows the variations in the monthly average concentrations for $\mathrm{PM}_{10}$ and $\mathrm{NO}_{\mathrm{X}}$ at the $\mathrm{Ku}$-Tin station in 2002. The consistency between $\mathrm{PM}_{10}$ and $\mathrm{NO}_{\mathrm{X}}$ is quite obvious. With this fact in mind, it is accepted that a temporary source must be in effect if the correlation between $\mathrm{PM}_{10}$ and $\mathrm{NO}_{\mathrm{X}}$ deviates far from the long-term track when viewed over a short 

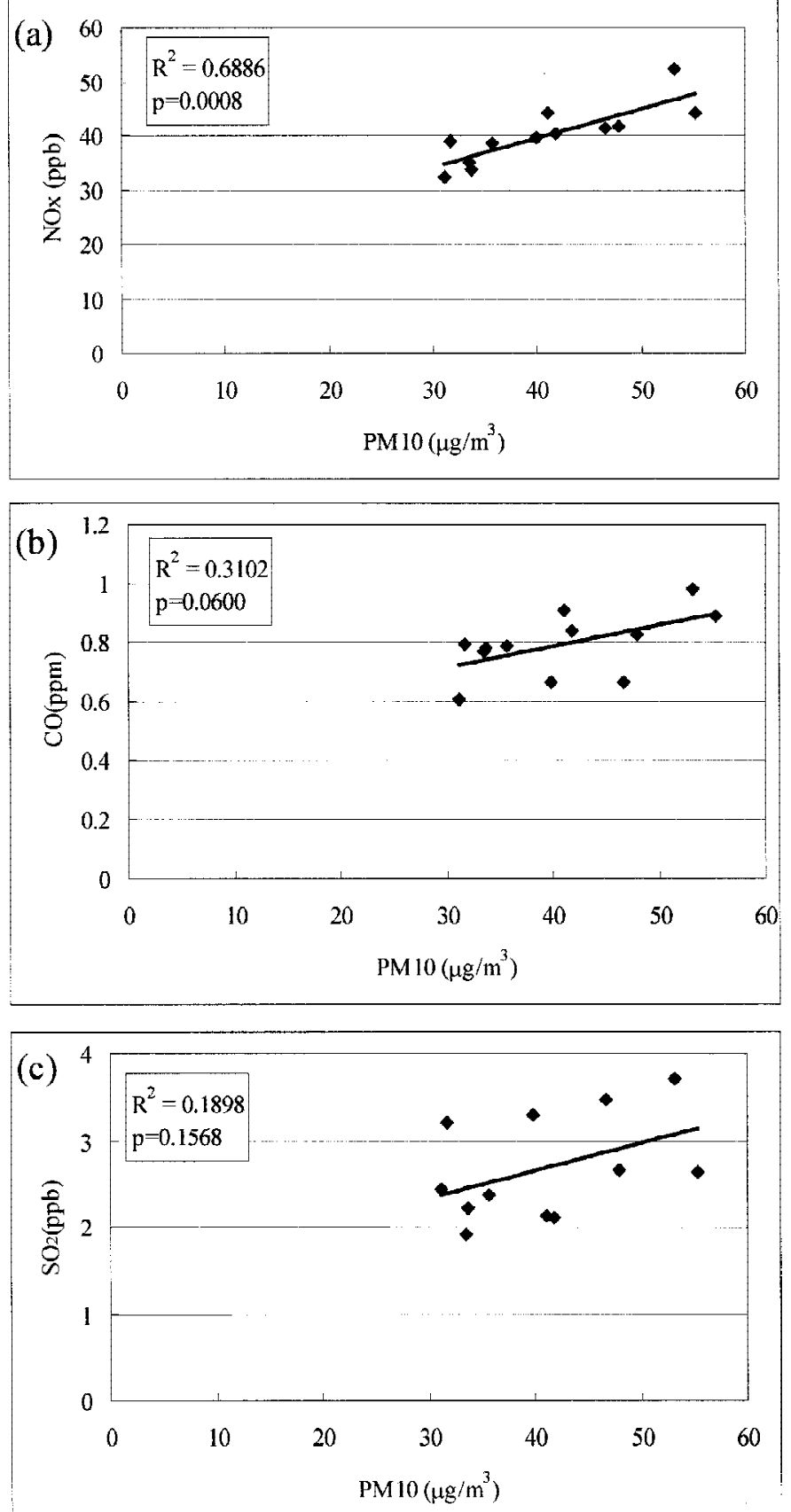

Fig. 7. Correlations between the $\mathrm{PM}_{10}$ concentration and the mixing ratios of critical gaseous pollutants monitored at the Ku-Tin station in 2002: (a) $\mathrm{PM}_{10}$ vs. $\mathrm{NO}_{\mathrm{X}}$; (b) $\mathrm{PM}_{10}$ vs. CO; (c) $\mathrm{PM}_{10}$ vs. $\mathrm{SO}_{2}$. 


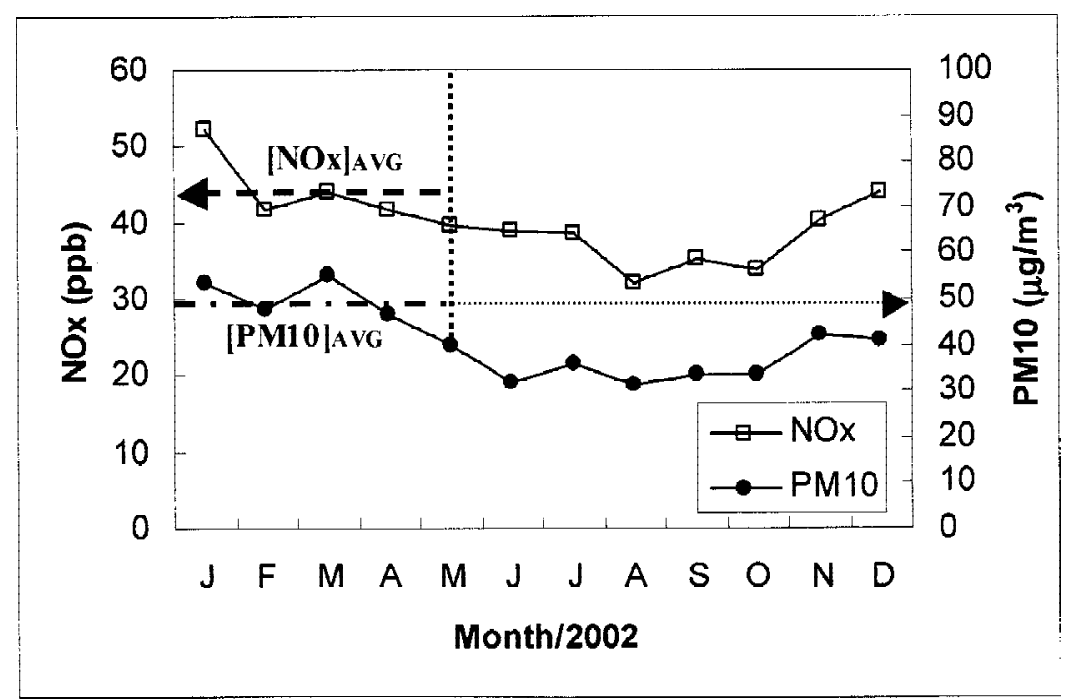

Fig. 8. Variations in monthly average $\mathrm{PM}_{10}$ and $\mathrm{NO}_{\mathrm{X}}$ concentrations at the KuTin station in 2002. The average concentrations over the first five months were taken as the basis for estimating the local $\mathrm{PM}_{10}$ contribution.

period. The time series plots in Fig. 3 clearly show that the $\mathrm{NO}_{\mathrm{X}}$ concentration decreased to a very low and steady level after a frontal passage, whereas $\mathrm{PM}_{10}$ increased sharply due to the presence of dust in the same period. To quantify the temporary source contribution to $\mathrm{PM}_{10}$, we defined " $\mathrm{PM}_{10}$ Anomaly" and "Anomaly Ratio" based on the long-term correlation between $\mathrm{PM}_{10}$ and $\mathrm{NO}_{\mathrm{X}}$ as follows:

$$
\mathrm{PM}_{10} \text { Anomaly }=\left[\mathrm{PM}_{10}\right]-\left[\mathrm{PM}_{10}\right]_{\mathrm{AVG}} \mathrm{x}\left\{\left\{\left[\mathrm{NO}_{\mathrm{X}}\right]-\left[\mathrm{NO}_{\mathrm{X}}\right]_{\mathrm{Wan}-\mathrm{Li}}\right\} /\left[\mathrm{NO}_{\mathrm{X}}\right]_{\mathrm{AVG}}\right\},
$$

and

Anomaly Ratio $=\mathrm{PM}_{10}$ Anomaly $/\left[\mathrm{PM}_{10}\right]$,

where $\left[\mathrm{PM}_{10}\right]$ and $\left[\mathrm{NO}_{\mathrm{X}}\right]$ are the $\mathrm{PM}_{10}$ and $\mathrm{NO}_{\mathrm{X}}$ concentrations in Taipei, respectively. $\left[\mathrm{NO}_{\mathrm{X}}\right]_{\mathrm{Wan}-\mathrm{Li}}$ is the simultaneous $\mathrm{NO}_{\mathrm{X}}$ concentration at Wan-Li, assumed to be the $\mathrm{NO}_{\mathrm{X}}$ concentration brought by the air parcel from the Asian continent. $\left[\mathrm{PM}_{10}\right]_{\mathrm{AVG}}$ and $\left[\mathrm{NO}_{\mathrm{X}}\right]_{\mathrm{AVG}}$ are the average $\mathrm{PM}_{10}$ and $\mathrm{NO}_{\mathrm{X}}$ concentrations in Taipei over the spring-months in 2002, respectively.

Table 2 summarizes the daily $\mathrm{PM}_{10}$ Anomaly Ratio, calculated from the air quality data from $\mathrm{Ku}$-Tin station, during each previously identified dust event. The Anomaly Ratio reached a high level of $86.8 \%$ on Feb. 11, the most intensive dust case in 2002. The long-range trans- 
port of Asian dust is surely not the only factor resulting in the $\mathrm{PM}_{10}$ Anomaly. In practice, a high $\mathrm{PM}_{10}$ Anomaly can also be found on a significant number of days besides the dust periods. Nevertheless, given that dust transport is the strongest factor affecting the $\mathrm{PM}_{10}$ concentration during the dust event periods, it is reasonable to attribute the $\mathrm{PM}_{10}$ Anomaly to Asian dust and assume the Anomaly Ratio as a maximum estimate for the contribution from Asian dust transport to the aerosol burden on the dust days. For the other three significant dust events, the estimated Asian dust contributions were 75.8, 62.5, and 62.5\% on Mar. 8, Mar. 18, and Apr. 9, respectively. The air quality impacts due to weak dust events were usually considered negli-

Table 2. Asian dust contributions to the local aerosol burden in Taipei during the identified Asian dust episodes.

\begin{tabular}{|c|c|c|c|c|}
\hline Event ID & Date & $\mathrm{PM}_{10}\left(\mu \mathrm{g} / \mathrm{m}^{3}\right)^{(\mathrm{a})}$ & $\mathrm{NO}_{\mathrm{x}}(\mathrm{ppb})^{(\mathrm{a})}$ & Anomaly Ratio of $\mathrm{PM}_{10}{ }^{(\mathrm{b})}$ \\
\hline \multicolumn{5}{|c|}{ Confirmed episode } \\
\hline C1 & Feb. 11 & 123 & 16.8 & 0.868 \\
\hline C2 & Feb. 12 & 95 & 34.2 & 0.675 \\
\hline \multirow{2}{*}{} & Mar. 6 & 71 & 30.0 & 0.574 \\
\hline & Mar. 7 & 58 & 30.1 & 0.513 \\
\hline C3 & Mar. 8 & 95 & 28.8 & 0.758 \\
\hline \multicolumn{2}{|c|}{ Mar. 9 } & 71 & 25.7 & 0.718 \\
\hline C4 & Mar. 18 & 78 & 28.8 & 0.625 \\
\hline C5 & Mar. 23 & 115 & 70.8 & 0.445 \\
\hline \multicolumn{7}{|c|}{ Apr. 9 } & 72 & 24.2 & 0.352 \\
\hline S1 & Feb. 9 & 79 & 28.2 & 0.625 \\
\hline & Feb. 10 & 51 & 33.5 & 0.672 \\
\hline
\end{tabular}

(a) Daily average monitored at EPA's Ku-Tin station.

(b) The $\mathrm{PM}_{10}$ anomaly is attributed to Asian dust during the given dust event periods. 
gible in relevant studies because of the relatively low $\mathrm{PM}_{10}$ levels on those days. However, the results from this study show some different aspects. On Mar. 23, for instance, the daily average $\mathrm{PM}_{10}$ concentration was only around $40 \mu \mathrm{g} \mathrm{m}^{-3}$, whereas the results of our analysis show that the Asian dust contribution to $\mathrm{PM}_{10}$ was noticeable. It reached $35.2 \%$, a level of about $14 \mu \mathrm{g} \mathrm{m}^{-3}$ in terms of the $\mathrm{PM}_{10}$ concentration. This is consistent with the relatively high aluminum content in the aerosol samples collected at that time (see Fig. 6). Thus, according to the results described above, long-range transport dust has important implications for local air quality during a dust episode, even if the dust event is not intense and overall $\mathrm{PM}_{10}$ levels are not high the contribution from Asian transport dust can still be significant.

\section{CONCLUSIONS}

Asian dust episodes identified using time series analysis of air quality data was compared with those identified using aerosol compositions. The observations show that high levels of aluminum in the ambient aerosols are usually associated with the suspected Asian-dust episodes identified by air quality inspection. The consistent results from two independent methods confirmed five Asian dust episodes in Taipei in the spring of 2002. Furthermore, we estimated the contribution of long-range transported aerosols to the ambient $\mathrm{PM}_{10}$ using a simplified method based on the observed correlation between $\mathrm{NO}_{\mathrm{X}}$ and $\mathrm{PM}_{10}$ in Taipei. Our results showed that the contribution of long-range transported aerosols to the local aerosol burden reached as high as $86.8 \%$ in the most intensive dust event that occurred on Feb. 11, 2002. For the weakest event on Mar. 23, 2002, the contribution was still at a noticeable level of 35\%, even it is not so obvious in terms of the $\mathrm{PM}_{10}$ concentration. With the fact that dust is the predominate aerosol species in the long-range transported air parcels during a dust episode, the $\mathrm{PM}_{10}$ Anomaly Ratio reported above was suggested as the maximal estimate of the Asian dust contribution to the local aerosol burden on a "dust day". Many more scientific insights regarding the long-range transport of natural material and anthropogenic pollutants can be obtained from extreme dust cases, although long-range Asian dust transport is a natural phenomenon, increasing industrial production over Eastern China undoubtedly necessitates more investigations into this issue.

Acknowledgments We are very grateful to the Reviewers for their constructive comments. This work was supported by Academia Sinica theme project "Particulate Matter and its Environmental Impacts in Taiwan", National Science Council grant NSC-92-2111-M-001-002 and Environment Protection Agency under contract EPA-91-FA11-03-A062.

\section{REFERENCES}

Chow, J. C., J. G. Watson, L. C. Pritchett, W. R. Pierson, C. A. Frazier, and R. G. Purcell, 1993: The DRI thermal/optical reflectance carbon analysis system: Description, evaluation and applications in U.S. air quality studies. Atmos. Environ., 27, 1185-1201. 
Duce, R. A., C. K. Unni, B. J. Ray, J. M. Prospero, and J. T. Merrill, 1980: Long-range atmospheric transport of soil dust from Asia to the tropical North Pacific: Temporal variability. Science, 209, 1522-1524.

Hsu, S. C. et al., 2004: Metal Compositions of $\mathrm{PM}_{10}$ and $\mathrm{PM}_{2.5}$ Aerosols in Taipei during the Spring, 2002. TAO, 15, 925-948.

Husar, R. B. et al., 2001: Asian dust events of April 1998. J. Geophys. Res., 106, $18317-$ 18330.

Iwasaka, Y., H. Minoura, and K. Nagaya, 1983: The transport and spatial scale of Asian duststorm clouds: A case study of the dust-storm event of April 1979.Tellus, Ser., 35, 189196.

Jaffe, D. et al., 1999: Transport of Asian air pollution to North America. Geophys. Res. Lett., 26, 711-714.

Kim, K., et al., 2003: The chemical composition of fine and coarse particles in relation with the Asian dust events. Atmos. Environ., 37, 753-765.

Lin, T. H., 2001: Long-range transport of yellow sand to Taiwan in spring 2000: observed evidence and simulation. Atmos. Environ., 35, 5873-5882.

Lin, C. Y. et al., 2004: Long-range transport of Asian dust and air pollutants to Taiwan.TAO, 15, 759-784.

Lung, S. C., C. H. Liu, S. Y. Huang, T. J. Lin, C. C. K. Chou, and S. C. Liu, 2004: Watersoluble ions of aerosols in Taipei in spring 2002.TAO, 15, 901-923.

Mamane, Y., and J. Gottlieb, 1989: Heterogeneous reactions of minerals with sulphur and nitrogen oxides. J. Aerosol Sci., 20, 303-311.

McKendry, I. G., J. P. Hacker, R. Stull, S. Sakiyama, D. Mignacca, and K. Reid, 2001: Longrange transport of Asian dust to the Lower Fraser Valley, British Columbia, Canada.J. Geophys. Res., 106, 18361-18370.

Murayama, T., et al., 2001: Ground-based net work observation of Asian dust events of April 1998 in East Asia. J. Geophys. Res., 106, 18,345-18,359.

Seinfeld, J. H., and S. N. Pandis, 1998: Atmospheric chemistry and physics. Wiley, New York.

Shaw, G. E., 1980: Transport of Asian desert aerosol to the Hawaiian Islands.J. Appl. Meteorol., 19, 1254-1259.

Terada, H., H. Ueda, and Z. Wang, 2002: Trend of acid rain and neutralization by yellow sand in East Asia - a numerical study. Atmos. Environ., 36, 503-509.

Tratt, D. M., R. J. Frouin, and D. L. Westphal, 2001: April 1998Asian dust event: A southern California perspective. J. Geophys. Res., 106, 18371-18380.

Uematsu, M., et al., 1983: Transport of mineral aerosol from Asia over the North Pacific Ocean. J. Geophys. Res., 88, 5343-5352.

VanCuren, R. A., and T. A. Cahill, 2002: Asian aerosols in North America: Frequency and concentration of fine dust. J. Geophys. Res., 107, 4804, doi:10.1029/2002JD002204.

Zhang, D., J. Zang, G. Shi, Y. Iwasaka, A. Matsuki, and D. Trochkine, 2003: Mixture state of individual Asian dust particles at a coastal site of Qingdao, China.Atmos. Environ., 37, 3895-3901. 